\title{
CBQT của Đại học Ngoại thương trên ấn phẩm hạng nhất chuyên ngành Operations Research
}

\author{
Vũ Thị Hạnh \\ Trường Đại học Ngoại thương \\ hanhvt@ftu.edu.vn
}

(Cập nhật bài SciComm trên SSHPA https://sc.sshpa.com/post/5523, ngày 17-07-2019)

\begin{abstract}
Nhiều công ty, đặc biệt ở các nền kinh tế mới nổi, không áp dụng những thực hành quản lý đơn giản và phổ biến, ví dụ như quản lý chất lượng (Quality Management - $Q M$ ) mặc cho lợi ích về hiệu suất được mang lại. Nguyên nhân của hiện tượng này và những phương pháp khuyến khích doanh nghiệp áp dụng thực hành quản lý là mối quan tâm lớn đối với các nhà nghiên cứu và hoạch định chính sách.

Hai tác giả Nguyễn Quang (Middlesex University London, Anh) và Kim Hương Trang (trường Đại học Ngoại thương) đã tập trung tìm hiểu vai trò can thiệp của Chính phủ trong việc thúc đẩy doanh nghiệp thực hành quản lý. Nghiên cứu "Promoting adoption of management practices from the outside: Insights from a randomized field experiment" được công bố trên tạp chí Journal of Operations Management.
\end{abstract}

JOURNAL OF

OPERATIONS MANAGEMENT

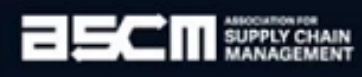

ORIGINAL ARTICLE

Promoting adoption of management practices from the outside: Insights from a randomized field experiment

Quang Nguyen $\mathbf{x}$. Trang Huong Kim $\mathbf{s}$

First published: 22 March 2019 | https://doi.org/10.1016/j.jom.2018.11.001

First published online by Elsevier BV on behalf of The Association for Supply Chain Management, Inc.

\% PDF $\&$ TOOLS $<$ SHARE

Ấn phẩm này thuộc hạng đầu bảng thế giới về chuyên ngành Operations Research và Decision Science với hệ số tác động cao hạng nhất, do NXB Wiley ấn hành. Cụ thể, 2018 JIF = 7.776 / CiteScore = 9.87, theo JCR 2019 và Scopus Data Release 5-2019 vừa qua. Trước năm 2019, tạp chí J Operations Management do NXB Elsevier phát hành. Như vậy, 
hai tác giả khi nộp bài nộp cho hệ thống Elsevier và khi lên bài thì lên ở hệ thống đối thủ cạnh tranh Wiley.

Nghiên cứu đã thử nghiệm đối chứng ngẫu nhiên đối với 328 doanh nghiệp vừa và nhỏ về dệt may tại Việt Nam. Bước đầu khảo sát nhận thức về quản lý chất lượng của người quản lý đồng thời là chủ sở hữu doanh nghiệp, sau đó chia doanh nghiệp thành 3 nhóm và tiến hành can thiệp thông tin một cách ngẫu nhiên: nhóm nhận được thông tin can thiệp, nhóm được sắp xếp cuộc gặp với Bộ Kế hoạch và Đầu tư, nhóm không nhận được sự can thiệp nào.

Kết quả nghiên cứu cho thấy Chính phủ có thể cung cấp thông tin, khuyến khích các doanh nghiệp thực hành quản lý. Ở cấp độ rộng hơn, đây là một phương pháp đạt hiệu quả chi phí, thúc đẩy thực hành quản lý và nâng cao chất lượng sản phẩm của các doanh nghiệp.

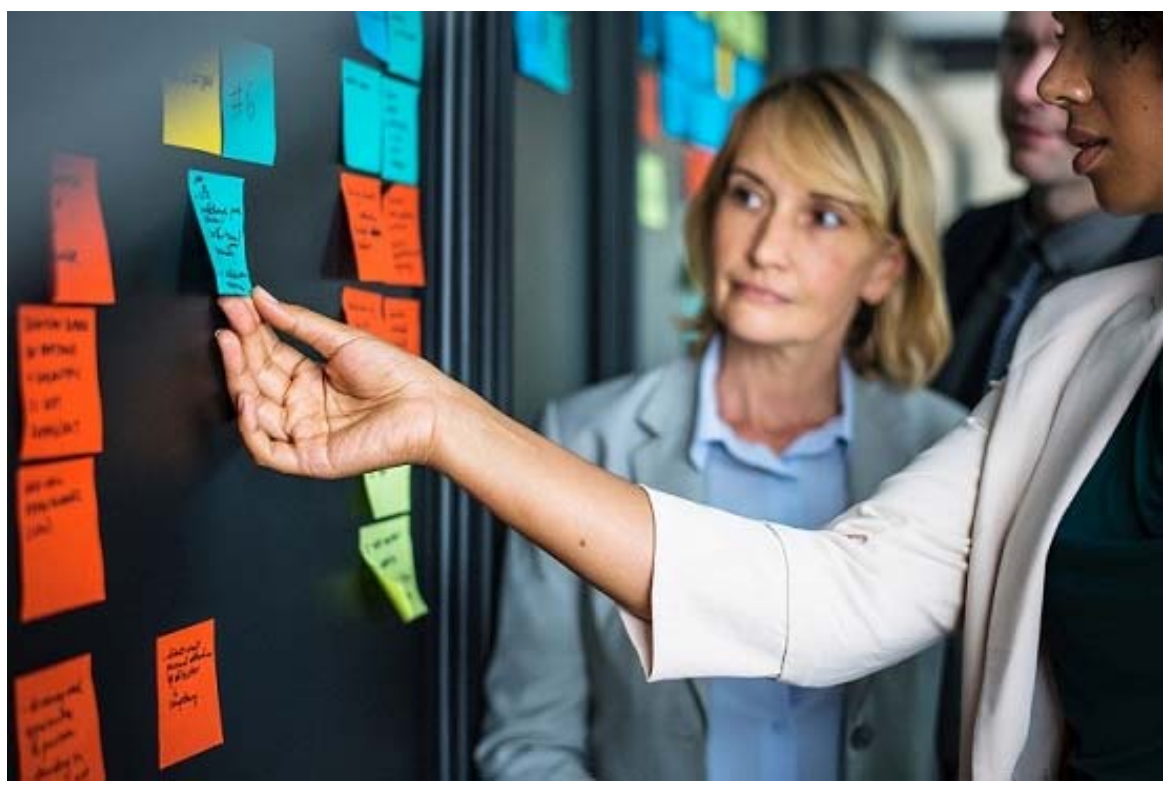

(Ảnh: https://www.pexels.com/photo/woman-touching-blue-sticky-note-1532191)

Các tác giả cũng đưa ra nhận định về sự phổ biến của những thực hành quản lý tiên tiến của các công ty đa quốc gia (MNEs) tại nước sở tại. Việc chia sẻ kiến thức từ những công ty này đóng vai trò quan trọng giúp phát triển các doanh nghiệp vừa và nhỏ trong nền kinh tế mới nổi. Do đó, nghiên cứu đề xuất với Chính phủ cơ chế tạo điều kiện, cung cấp cho MNEs thông tin về nhận thức của doanh nghiệp vừa và nhỏ về thực hành quản lý; về phía MNEs có thể đưa ra thông tin về lợi ích của việc áp dụng thực hiện quản lý, đặc biệt từ các doanh nghiệp vừa và nhỏ trong môi trường có mối liên hệ gần gũi. Cơ chế này có thể được kết hợp với các sáng kiến nhằm thúc đẩy thực hiện quản lý tại những thị trường mới nổi. 
Với bài trên tạp chí Journal of Operations Management của tác giả Kim Hương Trang, trường Đại học Ngoại thương trong năm 2018 giữ vị trí CBQT trên ấn phẩm có JIF cao thứ hai trong các nghiên cứu của giới KHXH\&NV Việt Nam, ngay sau Nature Human Behaviour (tham khảo: https://sc.sshpa.com/post/5507 và DOI: 10.1038/s41562-0170281-4).

\section{Tài liệu tham khảo:}

Nguyen, Q., \& Kim, H. T. (2019). Promoting adoption of management practices from the outside: Insights from a randomized field experiment. Journal of Operations Management, 65(1), 48-61. DOI: 10.1016/j.jom.2018.11.001.

Tran, T., Hanh VT, V. T., \& Hoang, H. P. (2019). Dấu ấn KHXHNV Việt trên các tạp chí quốc tế có hệ số tác động cao năm 2018. OSF Preprints, DOI: 10.31219/osf.io/vmcsz (July 1).

Vuong, Q. H. (2018). The (ir)rational consideration of the cost of science in transition economies. Nature Human Behaviour, 2(1), 5-5, DOI: 10.1038/s41562-017-02814. URL: https://www.nature.com/articles/s41562-017-0281-4. 